\title{
Farming in childhood, diet in adulthood and asthma history
}

\author{
R. Varraso*,\#, M.P. Oryszczyn*,\#, N. Mathieu", N. Le Moual*,\#, \\ M.C. Boutron-Ruault ${ }^{\#,+}$, F. Clavel-Chapelon ${ }^{\#,+}$, I. Romieu ${ }^{\S}$ and F. Kauffmann*,\#
}

ABSTRACT: The decrease in the number of children living on traditional farms in France during early childhood and changes in diet could both play a role in the increase in asthma prevalence over the last decades. This study aimed to assess 1) the association of farming lifestyle in childhood and asthma, and 2) whether diet in adulthood modifies the association between farming lifestyle in childhood and adult-onset asthma.

In the French Etude Epidemiologique des Femmes de la Mutuelle Générale de l'Education Nationale (E3N) study (54,018 females; age 43-68 yrs), three indicators of farming lifestyle were defined: one using individual data (having farmer parents) and two using ecological data (born in a rural area and exposure to cattle).

All farming lifestyle indicators were related to childhood- ( $<\mathbf{1 6}$ yrs) and adult-onset asthma (OR $(95 \% \mathrm{Cl})$ values for farmer parents were $0.54(0.42-0.70)$ and $0.72(0.62-0.84)$, respectively), and to diet in adulthood, in particular to high fruit and low wine intakes. The association between farmer parents and adult-onset asthma was not modified by diet in adulthood.

Results extend previous observations in younger cohorts on the protective role of contact with livestock and farming lifestyle on asthma, in particular during childhood.

KEYWORDS: Asthma, dietary patterns, farmer parents, lifestyle, livestock exposure

I ncreasing evidence for the role of early life events on chronic diseases in adults has led to the development of life-course epidemiology, with conceptual models incorporating pathways between biological and social factors for both the onset and progression of disease in adult life [1,2]. Asthma provides an example with potential biological pathways to explain both an association with a farming lifestyle [3] and with diet [4]. Optimal immunological maturation has been proposed to explain the protective effect against allergies of contact with livestock in the farming environment $[5,6]$. Studies in adolescents and adults have shown that the effect of a farming environment in childhood persists as a protective effect into adult life [7, 8]. Diet is also hypothesised to influence chronic respiratory diseases in adults through various biological mechanisms, such as modifying the antioxidant protection $[4,9,10]$.

A decrease in traditional farming and changes in diet are part of the changing environment and lifestyle, which could explain the increase in asthma prevalence over the last decades [11,12]. Diet is an essential aspect of lifestyle, with specificities between countries and social groups due to that are commonly and easily grown in a specific region frequently become a part of the local cuisine. The social context in which a child's eating patterns develop is important because the local environment serves as a model for the developing child [13]. In this context, a farming lifestyle in childhood may influence dietary habits in adulthood, but, to date, there have been no systematic studies.

No study has yet examined asthma in childhood and in adulthood, taking the farming environment in childhood and diet in adulthood into account simultaneously. Farming lifestyle and contact with livestock have rarely been assessed retrospectively, although this is possible through agricultural census and residential history information [14, 15]. In the Etude Epidemiologique des Femmes de la Mutuelle Générale de l'Education Nationale (E3N) [16], a large group of females born between 1925 and 1950, before major changes in traditional farming in France, were assessed: 1) for the association between farming lifestyle in childhood and asthma prevalence, with three indicators of farming lifestyle (having parents who were farmers, being born in a rural area and cultural, social and environmental factors. Foods

\section{AFFILIATIONS}

*Inserm, CESP Centre for Research in Epidemiology and Population Health, U1018, Respiratory and Environmental Epidemiology Team, \#Université Paris Sud 11, UMRS 1018 ,

+ Inserm, CESP Centre for Research in Epidemiology and Population Health, U1018, Nutrition, Hormones and Womens' Health Team, Villejuif, 'CNRS, UMR Ladyss (Social Dynamics and Reconstruction of Spaces), Paris, and §International Agency for Research on Cancer (IARC), Nutrition and Metabolism Section, Lyon, France.

CORRESPONDENCE

R. Varraso

Inserm CESP/U1018

Respiratory and Environmental Epidemiology Team

16 avenue Paul Vaillant Couturier 94807 Villejuif Cedex

France

E-mail: raphaelle.varraso@inserm.fr

Received:

April 222011

Accepted after revision:

May 192011

First published online:

June 092011 
being exposed to livestock); and 2) to consider whether diet in adulthood modified the association between farming lifestyle in childhood and adult-onset asthma.

\section{MATERIALS AND METHODS \\ Study population}

The E3N study is a prospective investigation of major chronic diseases among members from the Mutuelle Générale de l'Education Nationale, a national health insurance plan covering predominantly teachers [16]. This study began in 1990 and included 98,995 females aged 40-65 yrs. Follow-up questionnaires were sent every 2 yrs thereafter. In 1993, a validated dietary history questionnaire was sent to the participants. Part of the E3N cohort was then included in the European Prospective Investigation on Cancer. Standardised questions on asthma and data on farming lifestyle during childhood were included in the seventh follow-up questionnaire in 2003. For each questionnaire, the response rate was close to $85 \%$.

\section{Farming lifestyle}

Three farming lifestyle indicators were defined: one using individual data and two using ecological data. In 2003, female subjects were asked whether they had lived continuously on a farm for $\geqslant 3$ months during childhood, and, if answering yes, whether their parents were farmers. The first indicator of farming lifestyle was "farmer parents".

Using data from the General Agricultural Census (GAC), the commune at birth was categorised as rural when the number of inhabitants was $<5,000$ (to have a sensitive definition of rural). The second indicator of farming lifestyle was "birth in a rural area".

The literature on farming hypothesises that the endotoxin exposure that results from contact with livestock, cattle in particular, protects from allergic asthma [17]. Ecological scores were built in several steps. First, appropriate area and reference periods were chosen in an interdisciplinary research framework with geographers [17]. France is divided into geographical areas with various units: 22 regions, 96 departments, 3,644 cantons and 36,600 communes. An in-depth analysis of farming activities in two contrasted regions (Aquitaine, a vineyard region producing Bordeaux wine, and Normandy, a bovine region with Camembert production) was performed with the GAC for both 1955 (close to the year of birth of the females) and 1970 (the first computerised GAC). This analysis showed that the 1970 census was adequate to estimate the bovine density score in 1955 (high correlation between the two scores) and that appropriate assessment was obtained by grouping communes with $<1,000$ inhabitants from the same canton.

A "bovine score" was built based on the 1970 GAC for all French communes by combining the number of cattle per inhabitant and the size of the birth commune (table 1). Since $76 \%$ of the communes with $\geqslant 5,000$ inhabitants had $<0.1$ cattle per inhabitant, for females not born in rural communes, we allocated a bovine density score of 0 . Therefore, the bovine density score varied from 0 to 3 . Coherence was assessed both by geographical distribution with the expected agricultural heterogeneity within France (online supplementary fig. 1), and by the association of this score with the percentage of females who reported living on a farm (online supplementary fig. 2).

\begin{tabular}{|c|c|c|c|}
\hline \multirow[t]{3}{*}{ TABLE 1} & \multicolumn{3}{|c|}{$\begin{array}{l}\text { Construction of the bovine density score } \\
\text { according to the size of the birth commune and } \\
\text { to the number of cattle in the commune }\end{array}$} \\
\hline & & \multicolumn{2}{|c|}{ Inhabitants in the birth commune $\mathrm{n}$} \\
\hline & & $\geqslant 5000$ & $<5000^{\#}$ \\
\hline $\begin{array}{l}\text { Cattle per ir } \\
\text { birth com } \\
<1 \\
1 \\
\geqslant 2\end{array}$ & $\begin{array}{l}\text { abitant in the } \\
\text { une } n\end{array}$ & 0 (not rural) & $\begin{array}{c}1 \text { (low) } \\
2 \text { (medium) } \\
3 \text { (high) }\end{array}$ \\
\hline \multicolumn{4}{|c|}{$\begin{array}{l}\text { \#: the cut-off of } 5,000 \text { inhabitants was chosen to have a sensitive definition of } \\
\text { "rural". Data are taken from the } 1970 \text { General Agricultural Census, France. ': for } \\
\text { communes with }<1,000 \text { inhabitants, the number of cattle per inhabitant was taken } \\
\text { from the canton of birth, with small communes aggregated. For example, a female } \\
\text { born in a commune where the number of inhabitants was } 1,000-4,999 \text { and the } \\
\text { number of cattle per inhabitant was }>2 \text {, the bovine density score was classified in } \\
\text { category } 3 .^{+} \text {: among the } 1,448 \text { places with } \geqslant 5,000 \text { inhabitants, } 15.1 \% \text { of the } \\
\text { communes had } 0 \text { cattle per inhabitant, } 61.0 \% \text { had } \leqslant 0.1 \text { cattle per inhabitant (mean } \\
0.029 \text { ), } 22.8 \% \text { had } \leqslant 1 \text { cattle per inhabitant (mean } 0.252 \text { ), and only } 1.2 \% \text { had }>1 \\
\text { cattle per inhabitant (mean } 1.394 \text { ). }>76 \% \text { of the places with } \geqslant 5,000 \text { inhabitants } \\
\text { had }<0.1 \text { cattle per inhabitant, and } 99 \% \text { had }<1 \text { cattle per inhabitant. Therefore, for } \\
\text { females not born in rural communes, we allocated a bovine density score of } 0 \text {. }\end{array}$} \\
\hline
\end{tabular}

Similar scores were constructed for pigs, poultry, goats and sheep, with different categories for the number of livestock per inhabitant (online supplementary Methods section).

In order to investigate the specific contributions of the different exposures (farmer parents, birth in a rural area and the bovine density score) in relation to asthma risk, we assessed different combinations of exposures (farmer parents with exposure to cattle and farmer parents with being born in a rural area).

\section{Nutritional factor assessment}

Dietary patterns were developed using principal component analysis [18]. Briefly, food items were grouped a priori into 56 separate food groups and, as previously described [9], three dietary patterns were obtained from these food groups: a "prudent" pattern (high intake of fruit and vegetables), a "Western" pattern (high intake of pizza/salty pies, desserts, cured meats and pasta) and a "nuts and wine" pattern (high intake of nuts and seeds, salty biscuits, olives, wine and fortified wine) [9]. Each dietary pattern score was categorised into tertiles (tertile 1: the lowest score; tertile 3: the highest score). Total energy intake was estimated in 1993 through the dietary questionnaire and

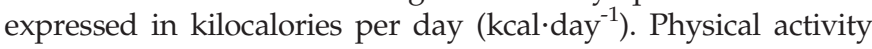
was assessed in 1993 and measured in metabolic equivalents per week $\left(\mathrm{MET} \cdot\right.$ week $\left.^{-1}\right)$. Body mass index (BMI) was calculated on the height and weight reported in 2003 and was used as a continuous and as a categorical variable $(<20,20-24.9,25-29.9$ and $\geqslant 30 \mathrm{~kg} \cdot \mathrm{m}^{-2}$ ).

\section{Asthma assessment}

Asthma, assessed by questionnaire, was investigated in 2003 and was defined as recommended by the American Thoracic Society (ATS): "Have you ever had asthma attacks?" and, if 
yes, "Was this diagnosis confirmed by a doctor?". For asthmatic females, age at the first attack and frequency of attacks in the last 12 months $(\geqslant 1$ per day, $\geqslant 1$ per week, $\geqslant 1$ per month and $<1$ per month) were recorded. We defined childhood asthma as $<16$ yrs and early childhood asthma $\leqslant 4$ yrs. The overall prevalence of childhood asthma was $1.6 \%$ and of adult-onset asthma, 3.2\%. Frequent asthma attacks were defined by a report of one or more attack per week in the last 12 months [9]. As the study was carried out by postal questionnaire, there was no lung function test.

\section{Statistical analysis}

Out of the 98,995 females included in the E3N study, 74,525 completed both the 1993 and the 2003 questionnaires. Among the 74,525 females, 19,542 were excluded because they had missing data for asthma $(n=17,646)$ or for information on farmer parents $(n=1,896)$. Among the remaining subjects, 965 additional females with extreme values of the ratio between energy intake and required energy were excluded. The present analysis is based on 54,018 females (online supplementary fig. 3). Among the 44,977 females that we excluded from the present analysis, the prevalence of ever having had asthma (using all the information available from the second follow-up questionnaire until the sixth follow-up questionnaire) was $6.0 \%$, and, when we looked specifically at the 20,507 females that we excluded from the analyses (who responded to the
1993 and the 2003 questionnaire but who had missing data), this prevalence was $5.6 \%$. These two prevalences were quite similar to the one reported in the present analysis $(6.5 \%)$. Among the 44,977 females that we excluded, we had information regarding the size of the birth commune for 40,272 of them: $35.8 \%$ were born in a rural place $(<5,000$ inhabitants). This prevalence was similar to the one reported in females included (35.7\%). Therefore, farming background and asthma were not overrepresented in the 44,977 females not included in the analyses. The comparison of females included $(n=54,018)$ and excluded due to missing data $(n=20,507)$ is presented in online supplementary table 1. Briefly, females included did not differ significantly from females excluded regarding the three indicators of farming lifestyle and asthma history (childhood- and adult-onset), but excluded females were older, less educated, had a higher BMI, were more often current smokers and took fewer multivitamin supplements.

The analysis strategy included two steps (fig. 1). First, we assessed the association between farming lifestyle in childhood with childhood- and adult-onset asthma. These associations were investigated using logistic regression models, both univariable and adjusted for potential mediators. For childhood asthma, models were adjusted for age, education level and pets in childhood. For adult-onset asthma, we further adjusted for smoking and nutritional factors, i.e. BMI, physical

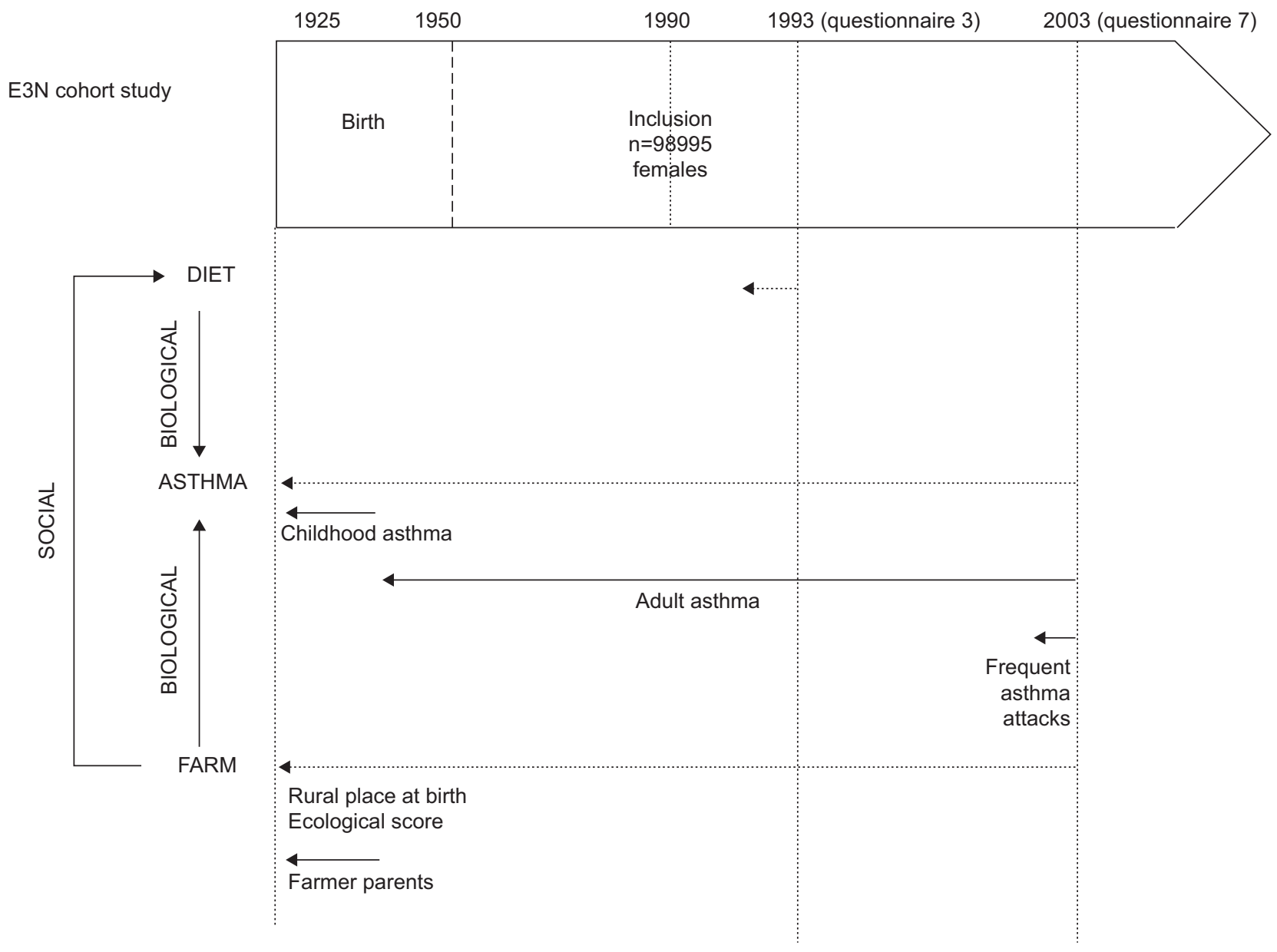

FIGURE 1. Study design and conceptual framework. E3N: Etude Epidemiologique des Femmes de la Mutuelle Générale de l'Education Nationale. 
TABLE 2 Characteristics of the population according to farmer parents, Etude Epidemiologique des Femmes de la Mutuelle Générale de l'Education Nationale (E3N) study, France

\begin{tabular}{|c|c|c|c|}
\hline Characteristic & No farmer parents ${ }^{\#}$ & Farmer parents ${ }^{\pi}$ & $\mathrm{p}$-value \\
\hline $\mathrm{Age}^{+}$yrs & $61.4 \pm 6.4$ & $61.3 \pm 6.3$ & 0.37 \\
\hline Born in a rural area ( $<5000$ inhabitants) & 29.5 & 78.9 & $<0.001$ \\
\hline \multicolumn{4}{|l|}{ Bovine density score, place of birth } \\
\hline 0 & 70.6 & 21.2 & \\
\hline 3 & 3.6 & 17.5 & \\
\hline \multicolumn{4}{|l|}{ Pets in childhood ${ }^{+}$} \\
\hline No pets & 44.3 & 9.0 & \\
\hline Cats only & 18.1 & 7.3 & \\
\hline Dogs only & 13.7 & 8.5 & $<0.001$ \\
\hline Ex-smoker & 31.2 & 26.0 & $<0.001$ \\
\hline Current smoker & 13.8 & 8.9 & \\
\hline \multicolumn{4}{|l|}{ Menopausal status $^{+}$} \\
\hline Pre-menopause & 4.6 & 5.2 & 0.09 \\
\hline Postmenopause & 95.4 & 94.7 & \\
\hline Peri-menopause & 0.1 & 0.1 & \\
\hline \multicolumn{4}{|l|}{ School education yrs } \\
\hline$\leqslant 11$ & 9.9 & 14.7 & \\
\hline $12-14$ & 50.4 & 61.9 & $<0.001$ \\
\hline $15-16$ & 19.8 & 14.3 & \\
\hline$\geqslant 17$ & 19.9 & 9.1 & \\
\hline \multicolumn{4}{|l|}{$B M I^{\mathfrak{s}} \mathbf{k g} \cdot \mathrm{m}^{-2}$} \\
\hline Total energy intake $\mathrm{kcal}^{\mathbf{5}} \mathrm{day}^{-1}$ & $2175 \pm 571$ & $2193 \pm 558$ & 0.01 \\
\hline Supplement use ${ }^{+, f}$ & 37.7 & 36.0 & 0.01 \\
\hline \multicolumn{4}{|l|}{ Food groups intake ${ }^{5} \mathrm{~g} \cdot \mathrm{day}^{-1}$} \\
\hline Fruit & $256.7 \pm 165.1$ & $287.8 \pm 175.0$ & $<0.001$ \\
\hline Vegetables & $226.8 \pm 150.5$ & $224.8 \pm 144.2$ & 0.29 \\
\hline Red meat & $49.1 \pm 37.1$ & $48.5 \pm 36.5$ & 0.20 \\
\hline Salty pies/pizza & $3.3 \pm 3.5$ & $2.9 \pm 3.1$ & $<0.001$ \\
\hline Cream desserts & $19.8 \pm 27.8$ & $19.0 \pm 25.5$ & 0.02 \\
\hline Processed meat & $30.8 \pm 22.9$ & $29.1 \pm 21.2$ & $<0.001$ \\
\hline Nuts and seeds & $5.7 \pm 5.5$ & $5.2 \pm 8.0$ & $<0.001$ \\
\hline Wine & $95.2 \pm 134.5$ & $72.8 \pm 105.5$ & $<0.001$ \\
\hline \multicolumn{4}{|l|}{ Prudent diet pattern } \\
\hline Tertile 1 (lowest score) & 32.0 & 31.3 & \\
\hline Tertile 2 & 34.2 & 33.1 & 0.03 \\
\hline Tertile 3 (highest score) & 33.8 & 35.5 & \\
\hline \multicolumn{4}{|l|}{ Western diet pattern } \\
\hline Tertile 1 (lowest score) & 32.3 & 31.1 & \\
\hline Tertile 2 & 34.0 & 36.2 & 0.77 \\
\hline Tertile 3 (highest score) & 33.7 & 32.7 & \\
\hline
\end{tabular}




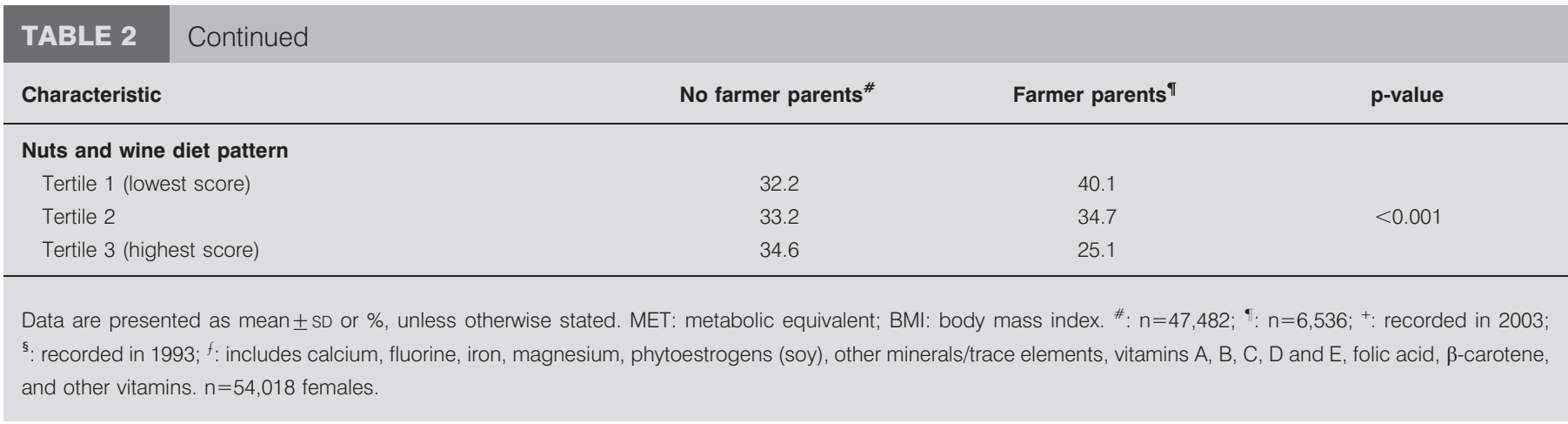

activity and diet (dietary patterns and total energy intake). We then assessed whether the association between farmer parents in childhood and adult-onset asthma was modified by diet in adulthood. We formulated two hypotheses. 1) Growing up on a farm protects against adult-onset asthma in participants with a diet in adulthood rich in fruit and vegetables (prudent diet), i.e. sources of antioxidants (biological aspects), but also a proxy for a healthy lifestyle (social aspects), although not in females with a low intake of fruit and vegetables. This hypothesis indicates a cumulative protective effect of both growing up on a farm and of a diet rich in fruit and vegetables (the same hypothesis was made for the nuts and wine pattern). 2) Growing up on a farm protects against adult-onset asthma in females with a diet in adulthood low in prepared foods, desserts and cured meats (Western diet), but not in females with a high intake of Western diet, i.e. sources of nitrites, trans fats and lipids (biological aspects), although this is also a proxy for an unhealthy lifestyle. This hypothesis indicates that the protective effect of growing up in a farm may be nullified by the high intake of a Western diet.

Since approximately one-third of the females were born during the Second World War and because living conditions on farms might have been quite different before, during and after the war, we stratified our analyses according to the year of birth $(n=17,961$ born before the war, i.e. between 1925 and 1938; $n=18,651$ born during the war, i.e. between 1939 and 1945; and $n=17,406$ born after the war, i.e. between 1946 and 1950). All analyses used SAS statistical software, version 9.1 (SAS Institute Inc., Cary, NC, USA).

\section{RESULTS}

\section{Farming lifestyle in the population}

$12 \%$ of females had farmer parents during childhood (table 2). Among females without farmer parents $(n=47,482), 5,284$ $(11 \%)$ had lived on a farm continuously for $\geqslant 3$ months during childhood. Females with farmer parents had more pets during childhood, were more often never-smokers and had a lower level of education than females without farmer parents. Regarding nutritional factors, females with farmer parents were more often overweight, had a higher total energy intake, took fewer supplements, and consumed more fruit and fewer salty pies/pizza, cream desserts, processed meat, nuts and seeds, and wine, than females without farmer parents. For the dietary patterns, having farmer parents during childhood was associated with a higher score of the prudent pattern and a lower score of the nuts and wine pattern in adulthood. No association was found with the Western pattern. Similar results were found after adjustments for age and total calorie intake.

\section{Farming lifestyle in childhood, dietary habits in adulthood and asthma history}

The three indicators of farming lifestyle were related to a history of early childhood- ( $\leqslant 4 \mathrm{yrs})$, childhood- ( $<16 \mathrm{yrs})$ and adult-onset of asthma, whereas no association was observed between frequent asthma attacks and farming lifestyle in either univariable or in adjusted models (table 3 ).

A history of asthma in childhood was negatively related to having a parent farmer (table 3), especially for early childhood asthma: OR (95\% CI) for farmer parents adjusted for age, education level and pets in childhood was $0.55(0.41-0.75)$ and p-value $<0.001$. Similar results were observed for adult-onset of asthma, even if the strength of the association was weaker.

Being born in a rural commune was associated with a lower risk of childhood and early childhood asthma (OR 0.83 (95\% CI $0.70-0.99), p=0.04$, for rural place adjusted for age, education level and pets in childhood). Similar results were observed for adult-onset of asthma, with an odds ratio closer to 1 .

Among females without missing data for the bovine density score $(n=48,328)$, a negative and significant trend was found between a history of childhood asthma and early childhood asthma: for the highest bovine density score versus the lowest score, odds ratio adjusted for age, education level and pets in childhood was $0.51(0.32-0.83)$, and the p-value trend was 0.02 . Similar results were reported for adult-onset of asthma, even if the strength of the association was weaker.

With regard to combined exposure to farmer parents and exposure to cattle (high versus low bovine density score), having farmer parents was more crucial in relation to childhood asthma than exposure to cattle: odds ratios adjusted for age, education level and pets in childhood were $0.50(0.36-$ $0.70), 0.77$ (0.59-1.00) and 0.61 (0.42-0.89), respectively, for "farmer parents and low bovine density score", "no farmer parents and high bovine density" and "farmer parents and high bovine density", as compared with "no farmer parents and low bovine density score". Regarding combined exposure to farmer parents and rural area at birth, having farmer parents was more crucial in relation to childhood asthma than being born in a rural area: odds ratios adjusted for age, education level and pets in childhood were 0.84 (0.72-0.99); 0.51 (0.30$0.87)$; 0.53 (0.40-0.72), respectively, for "rural place at birth and 


\begin{tabular}{|c|c|c|c|c|c|c|c|c|c|}
\hline \multirow{2}{*}{ TABLE 3} & \multicolumn{3}{|c|}{ Childhood asthma $<16$ yrs } & \multicolumn{3}{|c|}{ Adult-onset asthma } & \multicolumn{3}{|c|}{ Frequent asthma attacks in adulthood } \\
\hline & $\begin{array}{c}\text { Prevalence } \\
\%\end{array}$ & $\begin{array}{l}\text { Crude OR } \\
(95 \% \mathrm{Cl})\end{array}$ & $\begin{array}{l}\text { Adjusted OR } \\
(95 \% \mathrm{Cl})^{\#}\end{array}$ & $\begin{array}{c}\text { Prevalence } \\
\%\end{array}$ & $\begin{array}{c}\text { Crude OR } \\
(95 \% \mathrm{Cl})\end{array}$ & $\begin{array}{c}\text { Adjusted OR } \\
(95 \% \mathrm{Cl})^{\circ}\end{array}$ & $\begin{array}{c}\text { Prevalence } \\
\%\end{array}$ & $\begin{array}{c}\text { Crude OR } \\
(95 \% \mathrm{Cl})\end{array}$ & $\begin{array}{c}\text { Adjusted OR } \\
\text { (95\%Cl) }\end{array}$ \\
\hline Farmers & 1.1 & $\begin{array}{c}0.51 \\
(0.41-0.66)\end{array}$ & $\begin{array}{c}0.54 \\
(0.42-0.70)\end{array}$ & 3.5 & $\begin{array}{c}0.79 \\
(0.69-0.91)\end{array}$ & $\begin{array}{c}0.72 \\
(0.62-0.84)\end{array}$ & 19.2 & $\begin{array}{c}0.93 \\
(0.51-1.66)\end{array}$ & $\begin{array}{c}0.95 \\
(0.48-1.88)\end{array}$ \\
\hline p-value & & $<0.001$ & $<0.001$ & & $<0.001$ & $<0.001$ & & 0.80 & 0.88 \\
\hline \multicolumn{10}{|c|}{ Rural place at birth } \\
\hline $\begin{array}{l}\text { No ( } \geqslant 5000 \\
\text { inhabitants) }\end{array}$ & 2.3 & 1.00 & 1.00 & 4.4 & 1.00 & 1.00 & 20.7 & 1.00 & 1.00 \\
\hline \multicolumn{10}{|c|}{$\begin{array}{l}\text { Bovine density } \\
\text { score at place of } \\
\text { birth }^{+}\end{array}$} \\
\hline 0 & 2.3 & 1.00 & 1.00 & 4.4 & 1.00 & 1.00 & 20.6 & 1.00 & 1.00 \\
\hline 1 & 1.8 & $\begin{array}{c}0.78 \\
(0.66-0.92)\end{array}$ & $\begin{array}{c}0.84 \\
(0.70-0.99)\end{array}$ & 4.2 & $\begin{array}{c}0.97 \\
(0.87-1.08)\end{array}$ & $\begin{array}{c}0.93 \\
(0.83-1.05)\end{array}$ & 23.1 & $\begin{array}{c}1.16 \\
(0.77-1.74)\end{array}$ & $\begin{array}{c}1.16 \\
(0.72-1.83)\end{array}$ \\
\hline 2 & 1.6 & $\begin{array}{c}0.69 \\
(0.52-0.90)\end{array}$ & $\begin{array}{c}0.74 \\
(0.56-0.98)\end{array}$ & 3.3 & $\begin{array}{c}0.75 \\
(0.62-0.90)\end{array}$ & $\begin{array}{c}0.74 \\
(0.60-0.89)\end{array}$ & 19.5 & $\begin{array}{c}0.93 \\
(0.42-2.07)\end{array}$ & $\begin{array}{c}1.08 \\
(0.47-2.50)\end{array}$ \\
\hline 3 & 1.4 & $\begin{array}{c}0.62 \\
(0.44-0.88)\end{array}$ & $\begin{array}{c}0.69 \\
(0.49-0.98)\end{array}$ & 3.8 & $\begin{array}{c}0.86 \\
(0.69-1.06)\end{array}$ & $\begin{array}{c}0.78 \\
(0.63-0.98)\end{array}$ & 19.5 & $\begin{array}{c}0.93 \\
(0.42-2.07)\end{array}$ & $\begin{array}{c}1.01 \\
(0.43-2.36)\end{array}$ \\
\hline $\mathrm{p}$-value trend & & $<0.001$ & 0.002 & & 0.006 & $<0.001$ & & 0.96 & 0.78 \\
\hline
\end{tabular}

$\mathrm{n}=54,018$ females. ${ }^{*}$ : adjusted for age, education level and pets in childhood; ${ }^{\bullet}$ : adjusted for age, education level, pets in childhood, smoking, body mass index, physical activity, dietary patterns and total energy intake; ${ }^{+}: 0=$ not rural, $1=$ low bovine density score, $2=$ medium bovine density score, $3=$ high bovine density score (see Methods section).

no farmer parents", "nonrural place at birth and farmer parents" and "rural place at birth and farmer parents", as compared with "no rural place at birth and no farmer parents". Similar results were reported for adult-onset asthma.

Analyses were also stratified according to period of birth (before, during or after the war). For both childhood and adultonset asthma, the association between farmer parents and asthma history significantly persisted whatever the period of birth (OR 0.68 (95\% CI 0.51-0.91), 0.79 (0.62-1.00) and 0.67 (0.51-0.89), respectively, among females born before, during and after the war; the p-value for interaction between farmer parents and period of birth was 0.52), but for childhood asthma was stronger among females born after the war (0.62 (0.38$1.00), 0.68(0.46-1.00)$ and $0.34(0.21-0.57)$, respectively, among females born before, during and after the war; the p-value for interaction between farmer parents and period of birth (before and during versus after the war) was 0.04).

In each tertile of each dietary pattern (prudent, Western, and nuts and wine), we report a strong negative and significant association between farmer parents and adult-onset asthma (fig. 2). Other indicators of farming lifestyle (i.e. birth in a rural area and the bovine density score) led to similar results: diet in adulthood did not modify the association between farming lifestyle and adult-onset asthma.

\section{DISCUSSION}

Evidence regarding the role in respiratory diseases of farmingrelated conditions in childhood and dietary patterns in adulthood has been increasing. This is the first study to evaluate both factors in a large cohort of French females. We have proposed a construction of a bovine density score based on ecological data. The association of farming with childhood asthma was confirmed, whatever the indicator considered, i.e. the females' report of having farmer parents, as well as being based on the ecological indicators of being born in a rural commune or the bovine density within this commune. We also report a strong association between farming conditions in childhood and adult-onset asthma, an association not mediated by diet, BMI, smoking or physical activity in adulthood, which suggests a long-term beneficial effect of exposure independent of other environmental factors or behaviours in adulthood. When we combined the three indicators, having farmer parents was more crucial in relation to childhood asthma than exposure to cattle or being born in a rural area. Our interpretation is that personal exposure reported by having farmer parent corresponds to a higher level of exposure than exposure assessed by ecological data. We observed an association between farming lifestyle during childhood and dietary habits in adulthood. Farming lifestyle in childhood therefore predicts dietary habits, which have already been shown to be related to asthma and 


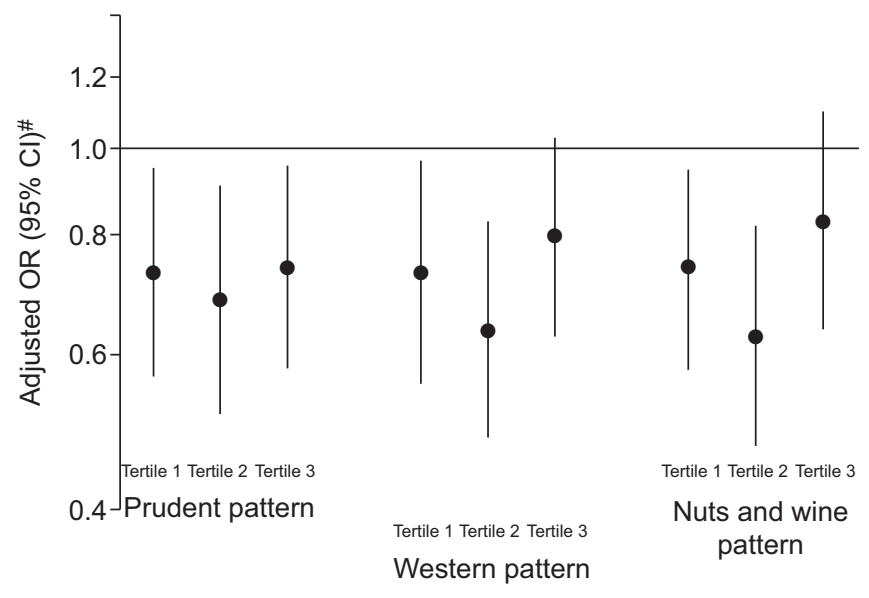

FIGURE 2. Association between farmer parents and adult-onset asthma, according to tertiles of dietary patterns, Etude Epidemiologique des Femmes de la Mutuelle Générale de l'Education Nationale (E3N) study, France. $n=54,018$ females. \#: adjusted for age, education level, pets in childhood, smoking, body mass index, physical activity, total energy intake and the two other dietary patterns (for each dietary pattern, the model is adujsted for the two other dietary patterns, i.e. for the prudent pattern, the two other dietary patterns adjusted for are the Western and the nuts and wine patterns, etc.).

to risk of chronic obstructive pulmonary disease, and is an important mediator to consider in the assessment of the role of diet in respiratory diseases. In the present study, the association between farming lifestyle in childhood and adult-onset asthma was not modified by dietary habits in adulthood.

Limitations of the present study were the lack of lung function data, that childhood asthma was only reported retrospectively, the limited information on early events and the lack of information information on diet before adulthood. We cannot exclude the possibility that an asthma diagnosis was more common in urban than in rural areas, for the same symptoms. However, the comparison of included and excluded females regarding asthma and farming lifestyle indicators showed no significant differences. Our results should be generalised with caution, as females from the E3N study are more educated than the general population and, therefore, might be more health conscious (i.e. fewer smokers, with a highest intake of fruit and vegetables, and more physically active). However, the strengths of the study are the availability of a large sample of females born before major changes in agriculture, which took place in the 1950s, and the social homogeneity of the population, combined with a wide geographical distribution over France.

\section{Feasibility and validation of ecological indicators of contact with livestock}

Retrospective indicators of contact with livestock were built using aggregated data. We showed the feasibility of the approach and a high correlation with information from the questionnaire (farmer parents and having lived on a farm during childhood). It is of particular interest in agricultural countries, such as France, with wide geographical heterogeneity (with farms for cereals and wine without livestock, or with regions with specific livestock well identified by their cheese production). As differential roles of cattle, sheep and poultry have been proposed [19], it would have been of interest to study in depth the potential role of other livestock, but this was not possible due to issues with sample size.

The retrospective evaluation of potential early contact with livestock was possible through the questionnaire (farmer parents) and by ecological scores using agricultural census data for the place of birth. This ecological approach used could easily be adapted in other countries. Furthermore, the construction of ecological indicators of rural lifestyle over the lifespan might be useful in a variety of settings (e.g. pesticide usage). The use of aggregated data, isolated and/or in conjugation with individuals' indices, could be further exploited [20]. It offers a way of decreasing the misclassification Berkson error (which occur where the same approximate exposure is used for many subjects), as emphasised in numerous theoretical reports [21]. However, disadvantages include the aspect of ecological fallacy regarding wrong interpretation at the individual level.

\section{Farming and dietary habits: a story of food preferences, availability and social factors}

Factors influencing food choice are based not only on individual preferences, but are constrained by circumstances that are social, cultural and economical. Several studies have reported a clear difference between social classes in food and nutrient intake; low-income groups in particular have a greater tendency to consume unbalanced diets and have a low intake of fruit and vegetables [22]. Numerous studies have investigated relationships between socio-demographic characteristics, lifestyle and dietary patterns [23-25], but few have reported the effect of urban versus rural living in adulthood on diet [24, 25].

The social context in which a child's eating pattern develops is important because the eating behaviour of people in the environment serves as a model for the developing child [13]. In that context, a farming lifestyle probably influences later food preferences, due to different food availability in rural areas, and a farming lifestyle was found to be related to a healthier behaviour regarding the intake of fruit and vegetables.

Farming lifestyle is also related to cultural behaviour, as drinking alcohol was not socially acceptable among females, especially 60 yrs ago. In our study, females without farmer parents drank more wine in adulthood than females with farmer parents. Two surveys have investigated the association between diet and urban/rural residence in adulthood, and they also reported that alcohol intake, especially wine, increased with urbanisation [24, 25].

Interestingly, we also observed a stronger association between farmer parents and childhood asthma among post-war-born females, as compared with females born before or during the war. It can be speculated that females born post-war were probably a more homogenous group regarding exposure to farming during childhood than those born during the war who experienced variable conditions (such as deprivation), or those born before the war who experienced changes during the war period.

\section{Farming, diet and asthma}

According to the hygiene hypothesis, the decrease in early contacts with infectious agents, in particular through contacts with livestock, could explain the increase in prevalence of 
asthma and allergies, and several studies have been conducted regarding farming lifestyle and asthma [6]. Our results on childhood asthma and farming lifestyle are consistent with previous studies [6]. The lower prevalence of adult-onset asthma in females born in a rural environment is consistent with the hypothesis of a beneficial effect of continuous exposure, independently of others environmental factors or behaviours in adulthood [26-31].

In studies on the farming hypothesis conducted in children, the role of diet has been evoked as a potential mediator in relation to changing lifestyle (i.e. changes in diet with urban living) $[7,32,33]$ and as a direct immunological mechanism $[8,34]$. In our study, we investigated whether diet in adulthood might modify the association between farming lifestyle in childhood- and adult-onset asthma, and we report no modifying effect of diet habits.

This study combined prospective and retrospective data to assess the effect of environment and lifestyle at various times over the lifespan. Results from this large French survey further support the hypothesis of contact with livestock and of a farming lifestyle resulting in lower asthma prevalence, particularly during in childhood.

\section{SUPPORT STATEMENT}

This work was supported by AFSSET - APR2003, ATC-Environment and Health 2003. The E3N study is supported by the Mutuelle Générale de l'Education Nationale (MGEN), the European Community, the French League against Cancer (LNCC), the Gustave Roussy Institute (IGR), the National Institute for Health and Medical Research (Inserm) and the General Councils of France.

\section{STATEMENT OF INTEREST}

None declared.

\section{ACKNOWLEDGEMENTS}

We wish to thank all the participants of the E3N study and L. Hoang, M. Niravong and M. Fangon (Inserm, CESP Centre for Research in Epidemiology and Population Health, Nutrition, Hormones and Women's Health Team, Villejuif, France) for invaluable assistance with the implementation of the study. We also thank B. Balkau (Inserm, CESP Centre for Research in Epidemiology and Population Health, Lifelong Epidemiology of Diabetes, Obesity, and Chronic Kidney Disease Team, Villejuif, France).

\section{REFERENCES}

1 Ben-Schlomo Y, Kuh D. A life course approach to chronic disease epidemiology: conceptual models, empirical challenges and interdisciplinary perspectives. Int J Epidemiol 2002; 31: 285-293.

2 Dunn KM. Extending conceptual frameworks: life course epidemiology for the study of back pain. BMC Musculoskelet Disord 2010; 11: 23.

3 Martinez FD. The origins of asthma and chronic obstructive pulmonary disease in early life. Proc Am Thorac Soc 2009; 6: 272-277.

4 Romieu I. Nutrition and lung health. Int J Tuberc Lung Dis 2005; 9: 362-374.

5 Strachan DP. Family size, infection and atopy: the first decade of the "hygiene hypothesis". Thorax 2000; 55: Suppl. 1, S2-S10.

6 Von Mutius E. Asthma and allergies in rural areas of Europe. Proc Am Thorac Soc 2007; 4: 212-216.
7 Ernst P, Cormier Y. Relative scarcity of asthma and atopy among rural adolescents raised on a farm. Am J Respir Crit Care Med 1999; 161: 1563-1566.

8 Leynaert B, Neukirch C, Jarvis D, et al. Does living on a farm during childhood protect against asthma, allergic rhinitis, and atopy in adulthood? Am J Respir Crit Care Med 2001; 164: 1829-1834.

9 Varraso R, Kauffmann F, Leynaert B, et al. Dietary patterns and asthma in the E3N study. Eur Respir J 2009; 33: 33-41.

10 Shaheen SO, Jameson KA, Syddall HE, et al. The relation of dietary patterns to adult lung function and chronic obstructive pulmonary disease. Eur Respir J 2010; 36: 277-284.

11 Devereux G. The increase in the prevalence of asthma and allergy: food for thought. Nat Rev Immunol 2006; 6: 869-874.

12 Becklake MR, Ernst P. Environmental factors. Lancet 1997; 350: Suppl. 2, SII10-SII13.

13 Birch LL, Fisher JO. Development of eating behaviours among children and adolescents. Paediatrics 1998; 101: 539-549.

14 Elliott L, Yeatts K, Loomis D. Ecological associations between asthma prevalence and potential exposure to farming. Eur Respir $J$ 2004; 24: 938-941.

15 Radon K, Schulze A, Ehrenstein V, et al. Environmental exposure to confined animal feeding operations and respiratory health of neighboring residents. Epidemiology 2007; 18: 300-307.

16 Clavel-Chapelon F, van Liere MJ, et al. E3N, a French cohort study on cancer risk factors. E3N Group. Etude Epidémiologique auprès de femmes de l'Education Nationale. Eur J Cancer Prev 1997; 6: 473-478.

17 Mathieu N, Oryszczyn MP, Hucy W, et al. Rurality and asthma: experience feedback from an interdisciplinary approach. In: Bley D, Gruénais MG, Vernazza-Licht N, eds. Health and Living Environment: Interdisciplinary Practices and North/South Crossed Views. Paris, IRD, 2010; pp. 99-124.

$18 \mathrm{Hu}$ FB. Dietary pattern analysis: a new direction in nutritional epidemiology. Curr Opin Lipidol 2002; 13: 3-9.

19 Ege MJ, Frei R, Bieli C, et al. Not all farming environments protect against the development of asthma and wheeze in children. J Allergy Clin Immunol 2007; 119: 1140-1147.

20 Kim HG, Richardson D, Loomis D, et al. Bias in the estimation of exposure effects with individual- or group-based exposure assessment. J Expo Sci Environ Epidemiol 2011; 21: 212-221.

21 Baker D, Nieuwenhuijsen MJ. Environmental Epidemiology: Study Methods and Application. New York, Oxford University Press, 2008.

22 Irala- Estévez JD, Groth M, Johansson L, et al. A systematic review of socio-economic differences in food habits in Europe: consumption of fruit and vegetables. Eur J Clin Nutr 2000; 54: 706-714.

23 Pala V, Sieri S, Masala G, et al. Associations between dietary pattern and lifestyle, anthropometry and other health indicators in the elderly participants of the EPIC-Italy cohort. Nutr Metab Cardiovasc Dis 2006; 16: 186-201.

24 Kesse-Guyot E, Bertrais S, Péneau S, et al. Dietary patterns and their sociodemographic and behavioural correlates in French middle-aged adults from the SU.VI.MAX cohort. Eur J Clin Nutr 2009; 63: 521-528.

25 Naska A, Fouskakis D, Oikonomou E, et al. DAFNE participants. Dietary patterns and their socio-demographic determinants in 10 European countries: data from the DAFNE databank. Eur J Clin Nutr 2006; 60: 181-190.

26 Douwes J, Travier N, Huang K, et al. Lifelong farm exposure may strongly reduce the risk of asthma in adults. Allergy 2007; 62: $1158-1165$.

27 Koskela HO, Happonen KK, Remes ST, et al. Effect of farming environment on sensitisation to allergens continues after childhood. Occup Environ Med 2005; 62: 607-611.

28 Portengen L, Sigsgaard T, Omland O, et al. Low prevalence of atopy in young Danish farmers and farming students born and raised on a farm. Clin Exp Allergy 2002; 32: 247-253. 
29 Radon K, Schulze A, Nowak D. Inverse association between farm animal contact and respiratory allergies in adulthood: protection, underreporting or selection? Allergy 2006; 61: 443-446.

30 Schultze A, van Strien R, Praml G, et al. Characterisation of asthma among adults with and without childhood farm contact. Eur Respir J 2007; 29: 1169-1173.

31 Eriksson J, Ekerljung L, Lötvall J, et al. Growing up on a farm leads to lifelong protection against allergic rhinitis. Allergy 2010; 65: 1397-1403.
32 Chatzi L, Apostolaki G, Bibakis I, et al. Protective effect of fruits, vegetables and the Mediterranean diet on asthma and allergies among children in Crete. Thorax 2007; 62: 677-683.

33 Filipiak B, Heinrigh J, Schäfer T, et al. Farming, rural lifestyle and atopy in adults from southern Germany - results from the MONICA/ KORA study Augsburg. Clin Exp Allergy 2001; 31: 1829-1838.

34 Riedler J, Braun-Fahrländer C, Eder W, et al. Exposure to farming in early life and development of asthma and allergy: a crosssectional survey. Lancet 2001; 358: 1129-1133. 